\title{
Research on Key Technologies of Construction Of Tunnel in Aeolian Stratum: A Case Study of Shenmu No. 1 Tunnel
}

\author{
Fei YE \\ Chang'an University \\ Xing Liang ( $\square$ trevorl@chd.edu.cn ) \\ Chang'an University \\ Xiaoming Liang \\ Chang'an University
}

\section{Research Article}

Keywords: Tunnel, Aeolian sand, Grouting, Stability analysis

Posted Date: July 27th, 2021

DOI: https://doi.org/10.21203/rs.3.rs-733467/v1

License: (c) This work is licensed under a Creative Commons Attribution 4.0 International License.

Read Full License 


\title{
Research on key technologies of construction of tunnel in aeolian stratum: a case
} study of Shenmu No. 1 tunnel

\author{
Xing Liang ${ }^{\mathrm{a}}$, Fei Ye ${ }^{\mathrm{b}}$, Xiaoming Liang ${ }^{\mathrm{c}}$
}

a Corresponding Author: Master degree candidate, School of Highway, Chang'an University, Xi'an, Shaanxi, China. E: TrevorL@chd.edu.cn

b Professor, School of Highway, Chang'an University, Xi'an, Shaanxi, China. E: xianyefei@126.com

c Master degree candidate, School of Highway, Chang'an University, Xi'an, Shaanxi, China.E: 1021031074@qq.com

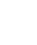

\begin{abstract}
The naturally formed aeolian sand dunes in northern Shaanxi have unique engineering characteristics. Several difficulties restrict the construction of road tunnels under this stratum, such as the poor self-stabilization ability of the surrounding rock, difficultly in injecting grout, and insufficient construction experience. Therefore, in this study, a case study of the Shenmu No. 1 tunnel was conducted to investigate the engineering characteristics of aeolian sand tunnels, compare the grouting effects of commonly used grouting materials, and discuss the reinforcement effects of different construction schemes in aeolian sand tunnels. Based on a field grouting test, it was found that it is difficult to inject ordinary cement grout into an aeolian sand layer; superfine cement grout and modified sodium silicate grout can be injected, but the former has a poor reinforcement effect. Through numerical analysis, it is found that an approach based on a concept of "horizontal jet grouting pile + benching partial excavation method with a temporary invert" is suitable for the construction of tunnels in aeolian sand in China.
\end{abstract}

Keywords: Tunnel; Aeolian sand; Grouting; Stability analysis

\section{Introduction}

Deserts and sandy land cover an area of total 1.54 million square kilometers in China, accounting for approximately $16 \%$ of the total territorial area. They are distributed in Xinjiang, Inner Mongolia, Qinghai, Gansu, and other northwestern regions, and accounting for $95.37 \%$ of these areas. An aeolian sand series results from the flow and movement of sand, and is characterized by its strong fluidity and ease of slip (Zheng, 2020; Qi et al., 2020; Yang et al., 2021; Ye et al., 2021;). Aeolian sand is the main landform in the desert areas. Owing to its engineering nature, transportation construction in desert areas has always been extremely difficult. Since the 1990s, China has completed aeolian sand tunnel projects such as the Xingshumao Tunnel, Jingpeng Tunnel, and Qiansongba Tunnel. However, because aeolian sand has strong fluidity and 
significantly different engineering properties from those of general strata, the factors to be considered during the design phase, construction phase, and accident management are relatively complicated. Accordingly, progress on projects in aeolian sand strata has been slow.

Many studies have been conducted on aeolian sand (Yuan et al., 2016; Zhang et al., 2020; Wang et al., 2019; Liu et al., 2019). However, because projects related to aeolian sand are relatively rare, the contributions of the current research are concentrated on the physical and mechanical properties of aeolian sand. Zhang (2009) studied the physical and chemical properties of aeolian sand in the Mu Us Desert and its engineering applicability. Liu (2012) thoroughly and systematically analyzed the feasibility of applying aeolian sand to highways from the perspectives of strength, compatibility, and stability. Wang (2018) identified the geochemical characteristics of surface fine-grained sediments in the mid-latitude deserts of Asia. Gao (2019) conducted a series of indoor mechanics experiments to analyze the influences of moisture content and density on the mechanical properties of aeolian sand, and summarized the mechanical characteristics and parameter change laws of aeolian sand. Zhang (2020) conducted experimental and numerical analyses to study the influence of sand deposition on a track structure. $\mathrm{Li}$ (2020) studied the utilization of aeolian sand for concrete production, and analyzed its workability and mechanical properties.

Factors such as sand leakage and sliding in the aeolian sand stratum can easily cause safety accidents such as large deformations of supports, collapses, and roof falls. As such, the construction of aeolian sand tunnels is considered very difficult and risky, and essentially can act as a bottleneck in engineering construction. In addition, there is no special and complete construction plan for aeolian sand. The responses to corresponding emergencies are insufficient. More generally, there is no well-formed, systematic, and available construction mode. At present, the number of aeolian sand tunnels being built (or that have been built) is relatively small; in most cases, the excavation can be barely be completed, and usually requires some means of strong support. However, with the increase in the number of tunnels being constructed in aeolian sandy strata in China, the shortcomings (such as insufficient construction experience and the lack of a well-formed systematic construction mode) have become increasingly prominent. Therefore, relevant research is urgently needed to guide the design and construction of tunnels in aeolian sand strata.

Scholars have conducted related research worldwide (Liu, 2009; Dong et al., 2011; Fan, 2017; Wan, 2019; Li, 2019; Li, 2021). Jin et al. (2006) adopted a pipe shed advanced support and found that the larger the effective range of the one-time support, the better the integrity of the support, and the higher the safety of the construction process. Qiu et al. (2012) and Zheng et al. (2012) analyzed the mechanical behaviors of aeolian sand tunnels during the construction process using Fast Lagrangian Analysis of Continua 3D $\left(\mathrm{FLAC}^{3 \mathrm{D}}\right.$ ) based on field monitoring data. The research primarily focused on an in- 
influences of construction steps on surrounding rock deformations under the action of support. Yan et al. (2014) identified and assessed the risk sources of collapse in aeolian sand tunnels based on a fuzzy evaluation method, expert investigation method, and analytic hierarchy process, and determined risk indicators. They indicated that construction/design factors and the choice of advanced support were the most important one-level and two-level factors, respectively. Wang et al. (2017) used the discrete element software UDEC to analyze the reinforcement effects of vertical jet grouting piles and horizontal jet grouting piles in aeolian sand tunnels. Many researchers have studied the feasibility of jet grouting in tunneling projects (e.g., Wang et al., 2019). Wang et al. (2020) proposed a theoretical approach for evaluating the variations in the excess pore water pressure caused by the installation of a jet grouting column in clay. Shen et al. (2021) proposed a framework for incorporating a bidirectional long shortterm memory and data sequencing to predict the diameters of jet grouted columns in soft soil in real time.

However, relatively few studies have considered the applicability of grout and advanced grouting technology in aeolian sand, especially based on in situ tests. Moreover, the construction technologies have not been compared in detail, nor has an optimum technology been identified. Accordingly, this study uses the Shenmu No. 1 tunnel as an example to conduct research on a construction technology for shallow highway tunnels in aeolian sand strata, aiming to solve technical problems in aeolian sand tunnel grouting and construction technology, and to ensure the construction safety and engineering quality of aeolian sand tunnels; these issues are of great engineering practical significance.

\section{Background}

\subsection{Geological characteristics of aeolian sand for Shenmu No. 1 tunnel}

\subsubsection{Physical properties}

The Shenmu No. 1 Tunnel in the Yu-Shen Highway is located on the edge of the Mu Us Desert. The aeolian sand in that location is generally brownish-yellow, loose, and slightly wet. It is primarily composed of feldspar (73\%) and fine quartz sand (23\%), followed by silt sand and silty soil, which are concentrated at the tunnel exit and in the surface above the tunnel, with a thickness of the covering layer between 15 and $35 \mathrm{~m}$. The main physical and mechanical indexes as obtained through field experiments are listed in Table 1, and the particle size distributions are listed in Table 2. In this study, the method adopted for separating particles was a sieving method (Test Methods of Soils for Highway Engineering JTG E40-2007). The particles were mostly composed of fine sand $(0.075-0.25 \mathrm{~mm})$, followed by very fine sand $(0.01-0.075 \mathrm{~mm})$, and medium sand $(0.25-0.5 \mathrm{~mm})$; sand with a size greater than $0.5 \mathrm{~mm}$ was rare. The uneven coefficient $C_{u}$ was 3.5 , and the curvature coefficient $C_{c}$ was 0.64 , indicating poor gradation. 
119 Physical and mechanical indexes of aeolian sand.

\begin{tabular}{|c|c|c|c|c|c|c|c|}
\hline $\begin{array}{l}\text { Sampling } \\
\text { location }\end{array}$ & $\begin{array}{l}\text { Water } \\
\text { conte } \\
\text { nt } \\
(\%)\end{array}$ & $\begin{array}{l}\text { Natur } \\
\text { al void } \\
\text { ratio }\end{array}$ & $\begin{array}{l}\text { Natura } \\
1 \text { bulk } \\
\text { density } \\
\left(\mathrm{kN} / \mathrm{m}^{3}\right. \\
)\end{array}$ & $\begin{array}{l}\text { Cohesio } \\
\mathrm{n} \\
(\mathrm{MPa})\end{array}$ & $\begin{array}{l}\text { Intern } \\
\text { al } \\
\text { frictio } \\
\mathrm{n} \\
\text { angle }\end{array}$ & $\begin{array}{l}\text { Modulus } \\
\text { of } \\
\text { deformatio } \\
\mathrm{n} \\
(\mathrm{MPa})\end{array}$ & $\begin{array}{l}\text { Permeabili } \\
\text { ty } \\
\text { coefficient } \\
(\mathrm{cm} / \mathrm{s})\end{array}$ \\
\hline $\begin{array}{l}\mathrm{ZK} 91+23 \\
2\end{array}$ & 4.4 & 0.447 & 17.155 & 0.011 & 26.88 & 21.0 & 3.56 \\
\hline $\mathrm{K} 91+240$ & 4.8 & 0.456 & 17.165 & 0.012 & 27.65 & 22.0 & 3.50 \\
\hline
\end{tabular}

120 Note: tests for physical and mechanical indexes were carried out based on Test 121 Methods of Soils for Highway Engineering (JTG E40-2007).

122 Table 2

123 Gradation of grain of aeolian sand (\%)

\begin{tabular}{llllll}
\hline \multirow{2}{*}{ Sampling location } & \multicolumn{7}{c}{ Grain size $(\mathrm{d} / \mathrm{mm})$} & & \\
& $>1.0$ & $1.0-0.5$ & $0.5-0.25$ & $0.25-0.075$ & $<0.075$ \\
\hline ZK91+232 & 0 & 2.1 & 19.7 & 47.6 & 30.6 \\
K91+240 & 0 & 4.3 & 18.5 & 47.9 & 29.3 \\
\hline
\end{tabular}

124 From the physical and mechanical indexes and gradation of the aeolian sand, it can be 125 seen that its particles have the characteristics of a small cohesive force, poor gradation, 126 low compressibility, inclination to disturbances owing to excavation, strong water 127 permeability, and a relatively low shear strength.

\subsubsection{Mechanical properties}

129 (1) Compressibility

130 Aeolian sand has a single-grain structure, and its compression primarily depends on the 131 rearrangement and fragmentation of the particles. Under the action of low pressure, the 132 particles slip and roll, making the soil denser and more stable. The amount of 133 compression is determined by the frictional resistance between the particles against 134 displacement. The better the gradation and the higher the density, the greater the 135 resistance and the smaller the compression deformation. The compression process of 136 aeolian sand is almost instantaneous sinking, followed by long-term deformation with 137 a deceleration rate; this represents the process of gradually adjusting the position of the 138 particles to overcome resistance. The compressibility coefficient of aeolian sand is 139 generally small (less than $0.1 \mathrm{MPa}^{-1}$ ), showing low compressibility. 
141 The strength characteristics, especially the density values under various water contents, 142 play an important role in grout injection. Under the same water content, when the dry 143 density of aeolian sand is higher, the corresponding internal friction angle and cohesion 144 are higher. Under the condition of the same dry density, when the water content is 145 smaller, the internal friction angle and cohesion are smaller. Furthermore, the higher 146 the dry density, the higher the shear strength. Under the same dry density and vertical 147 pressure, the water content has little effect on the shear strength; the difference in the 148 strength value is approximately $10 \mathrm{kPa}$. Under the influence of capillary force, given 149 that the vertical pressure is small, when the water content is less than a certain value $150(14 \%)$, the shear strength increases with an increase in water content, and when the 151 water content is greater than a certain value (14\%), the shear strength decreases with an 152 increase in water content.

\section{$153 \quad 2.2$ General information of Shenmu No. 1 tunnel}

154 The Shenmu No. 1 Tunnel adopts the form of two independent single-hole tunnels separated from the upper and lower sides. The starting and ending pile numbers of the left line are ZK90+998-ZK91+360, and the length is $362 \mathrm{~m}$. The starting and ending pile numbers of the right line are K90+993-K91+345, and the length is $352 \mathrm{~m}$. The tunnel was constructed using a shallow tunneling method, with a steel arch, steel mesh, and shotcrete as the initial support, and molded concrete as the secondary lining. The horizontal profile is shown in Fig. 1.

161 According to the results from a ground survey, drilling, and geophysical prospecting, 162 there is Quaternary Holocene aeolian sand $\left(\mathrm{Q}_{4}{ }^{\mathrm{eol}}\right)$ overlying the tunnel site area, and 163 Triassic fine sandstone underlying the tunnel. The soil layers from top to bottom are as 164 follows: aeolian sand layer, and then fully weathered-strongly weathered fine sandstone.

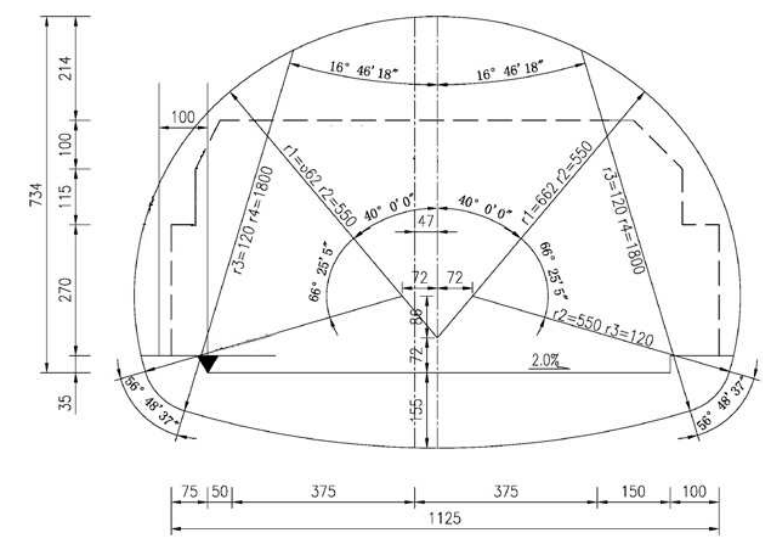

168 An advanced small pipe grouting support method was adopted in the early construction 
stage of the Shenmu No. 1 tunnel, in combination with a four-step excavation method.

170 During the construction, severe sand leakage and sand sliding occurred in the tunnel

171 face and side walls; the primary support sank overall and invaded the tunnel clearance,

172 and a depression cone (up to $10 \mathrm{~m}$ in diameter) and cracks (up to $3 \mathrm{~cm}$ wide) appeared on the surface (Fig. 2 and Fig. 2). There were two potential causes considered for the sand leakage and development of cracks: (1) the sliding surface of the sand body extended to the ground, indicating that the sliding surface of the sand body may have exceeded the scope of the advance support and pre-reinforcement; and (2) the grouting of the advance support failed to achieve the designed reinforcement effect, and the soil

179 above the vault slid into the tunnel along the gap between the grouting pipes.

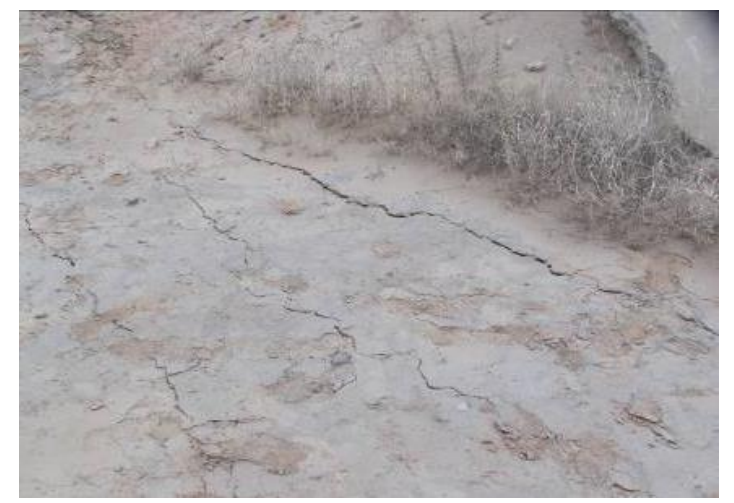

Fig. 2 Cracks on the surface

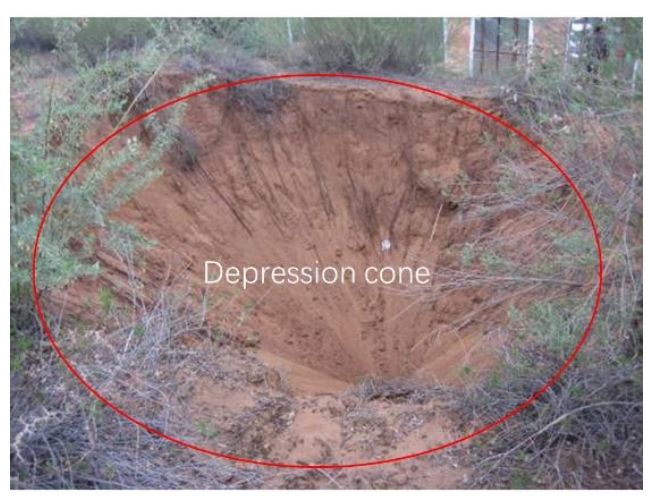

Fig. 3 Depression cone on the surface

In summary, the key problem in the construction of aeolian sand tunnels is sand leakage. This section discusses field grouting tests conducted using different grouting methods and materials. The geological characteristics, grouting mechanism(s) of aeolian sand strata, and existing problems in the grouting process are summarized and studied, hoping to promote the further development of grouting technology, expand its application range, and solve technical problems in similar projects.

\subsection{Field grouting test}

With respect to the geological conditions of the Shenmu No. 1 tunnel, the effect of grouting is a key factor in controlling the surface settlement and ensuring construction safety. Simply using an engineering analogy method and/or semi-empirical engineering method to determine the grouting parameters will bring great risks. Therefore, to better understand the grouting characteristics of the formation, obtain the necessary technical and economic data, and demonstrate the rationality of the grouting scheme, a representative section should be selected for field grouting tests before grouting construction (Fig. 4). 


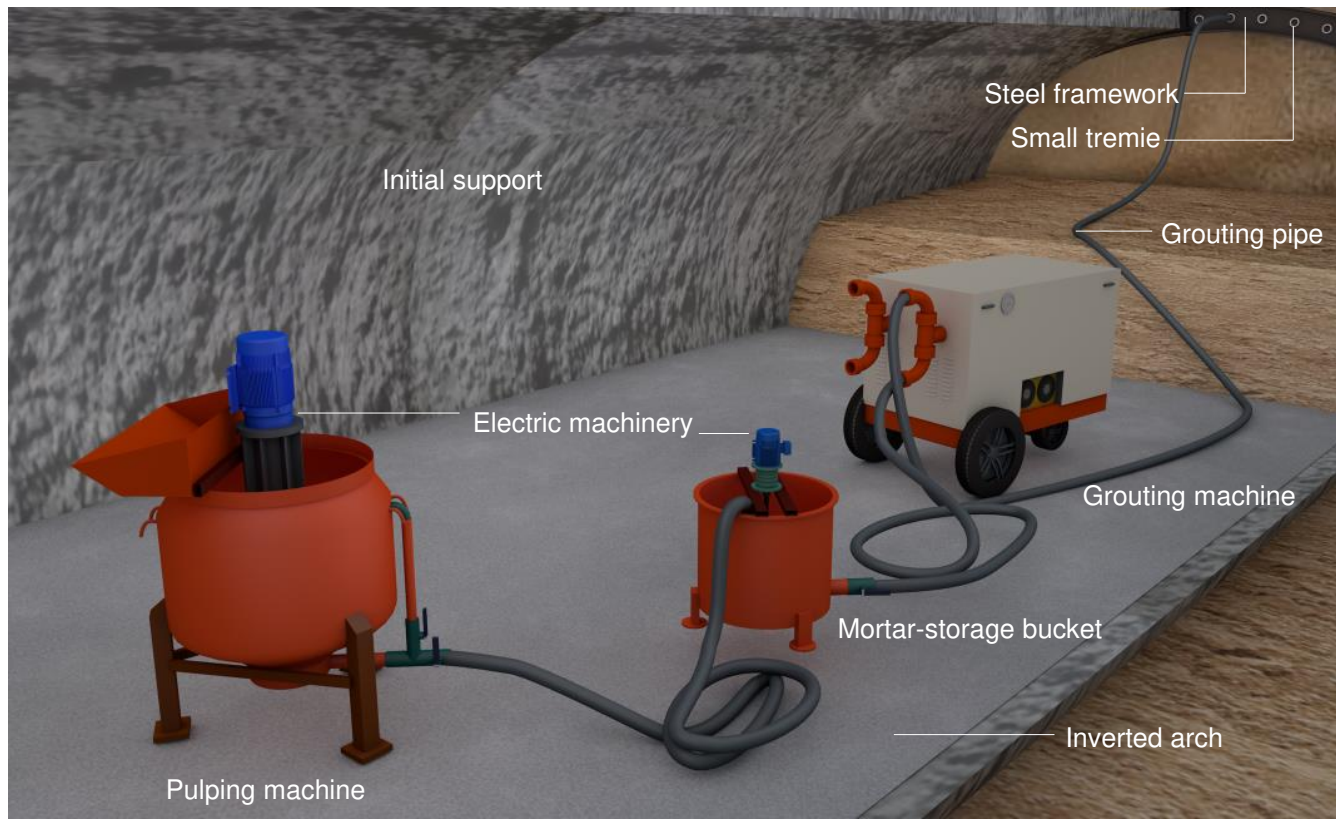

Fig. 4 Sketch map of grouting inside tunnel

198 Based on the understanding of the basic properties of various grouting materials, in this 199 study, the test combined the engineering geological conditions, hydrogeological 200 conditions, and criticality class of the grouting in the aeolian sand section of the Shenmu 201 No. 1 Tunnel. A penetration grouting method was selected to evaluate the advantages 202 and disadvantages of each grouting material and grouting method through the analysis 203 of test data, and to optimize the grouting ratio scheme.

\section{4 (1) Ordinary Portland cement grout}

At K91+225 of the right tunnel, a series of $\varphi 50$ small pipes were installed outside the excavation contour line of the upper part of the tunnel. The circumferential spacing of the pipes was $30 \mathrm{~cm}$. A total of 51 pipes were installed in three sections, with a range of $120^{\circ}$ in the upper tunnel profile, i.e., 17 pipes were located in each pilot area, with the whole section being divided into three pilot areas on the left, middle, and right (Fig.

210 5). Three grouts with various water-cement ratios, i.e., $m_{w}: m_{c}=0.8: 1,1: 1$, and 1.5:1,

211 were adopted to carry out in-situ tests in the three pilot areas. All grouting construction 212 was completed on the first day, and the excavation was conducted the next day to 213 examine the grouting effect.

214 During the test, the value of the grouting pressure gauge increased rapidly and reached 215 the final pressure value within a short time (10 s-20 s). Once the grouting volume no 216 longer changed, it was found that the final volume was much smaller than the design 217 grouting amount. The grout failed to spread, and did not meet the design reinforcement 218 requirements. After excavation, it was revealed that there was no penetration of grout 219 into the aeolian sand layer. However, grout clusters with diameters of 2-10 cm appeared around the holes of the small tremies. These grout clusters failed to form a whole 
reinforced body; therefore, the sand leakage remained serious during the excavation. Although the grouting amounts of the three grouts were different, the reinforcement effects were not significantly different. Ordinary Portland cement grout has difficulty permeating in to aeolian sand formations; this is because ordinary Portland cement has a large particle size, and is therefore difficult to inject into an aeolian sand layer with pores of $10 \mu \mathrm{m}$. Furthermore, the cement particles are suspended in the slurry; thus, even if the particles are smaller than the pores of the sand layer, owing to the filtering effect of the sand layer, the penetration range is extremely small, and sometimes the slurry consolidates around the grouting holes. Therefore, based on the principle of particle size matching, this grout was considered as only suitable for broken rock layers or coarse gravel sand layers, and was not suitable for aeolian sand layers.

Fig. 5 Layout of grouting pipes in vault area

\section{4 (2) Superfine cement grout}

At K91+245 of the left tunnel, the ordinary cement was changed to superfine cement for testing. Three grouts with various water-cement ratios, that is, $m_{w}: m_{c}=1: 1,1.5: 1$, and 2:1, were adopted to conducted in-situ tests in the three pilot areas (Fig. 6).

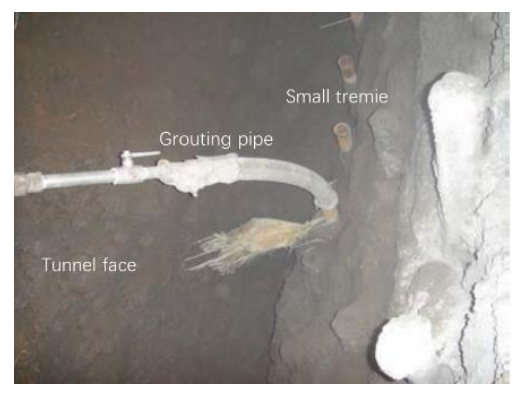

Fig. 6 In-situ test of superfine cement grout

240 During the test, the value of the grouting pressure gauge increased rapidly and reached 241 the final pressure value in a relatively short time (20s-30s). Once the grouting volume no longer changed, it was found that the final volume was smaller than the design 
grouting amount. The grout failed to spread well, and it could not meet the design reinforcement requirements. After excavation, it was revealed that a heterogeneous penetration of grout existed in the aeolian sand layer, and that the radius of penetration was small. Similar to the results from the test of the ordinary Portland cement grout, grout clusters with diameters of 2-10 appeared $\mathrm{cm}$ around the holes of the small pipes. Although the grouting amounts of the three grout were different, the reinforcement effects were not significantly different. The superfine cement grout had a small particle size, with an average particle size of $4 \mu \mathrm{m}$. Theoretically, it could be injected into the aeolian sand layer with a pore size of $10 \mu \mathrm{m}$; however, the difference in the reinforcement effect compared with that of ordinary cement grout was not large, primarily because the superfine cement grout was prone to sediment, and the selfstability was poor. Superfine cement grout can penetrate aeolian sand formations, and could potentially be adopted as a high-quality grouting material; however, its stability and grouting technology need to be further improved to make good use of its advantages.

(3) Modified sodium silicate grout

After the superfine cement grouting test was completed, to avoid affecting the normal construction in the tunnel, a modified sodium silicate grouting test was selected for the roadbed outside the exit of the right tunnel. In particular, $\varphi 50$ small pipes were placed horizontally along the side slope of the roadbed. The pipe length was $4.5 \mathrm{~m}$ and the spacing was $30 \mathrm{~cm}$, for a total of 15 pipes. The test was divided into three groups, with five small pipes in each group (Fig. 7).

264 During the test, the injectability of the grout was significantly improved, and the permeability was better than the above two grouting tests in the aeolian sand formations; however, the gelation time of the modified sodium silicate grout was difficult to control, and the grouting process was complicated, causing the grout volume to be less than the design grouting amount.

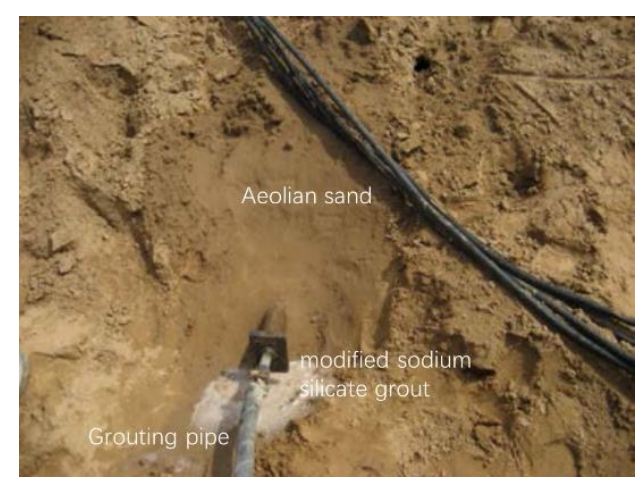

271 After excavation, it was revealed that there was uniform grout penetration in the aeolian 272 sand formation. Grout clusters with diameters of 8-10 $\mathrm{cm}$ around the holes of the small 273 pipes appeared; the strength of these was so low that they could be broken if subjected 
to pressure by hand. Furthermore, the grout condensed into white flocs after being 275 exposed to air for a period of time.

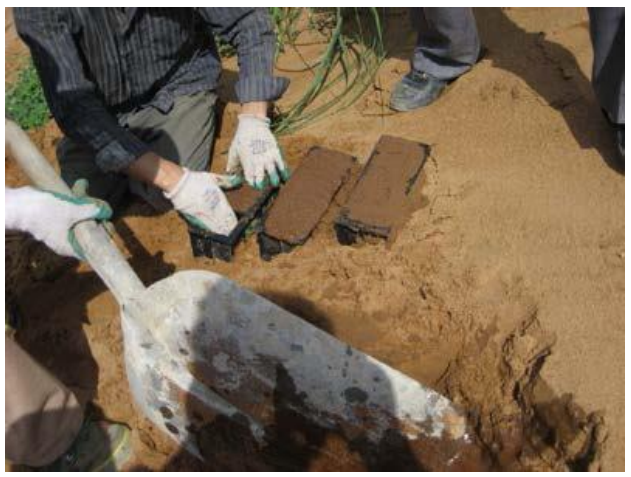

(a)

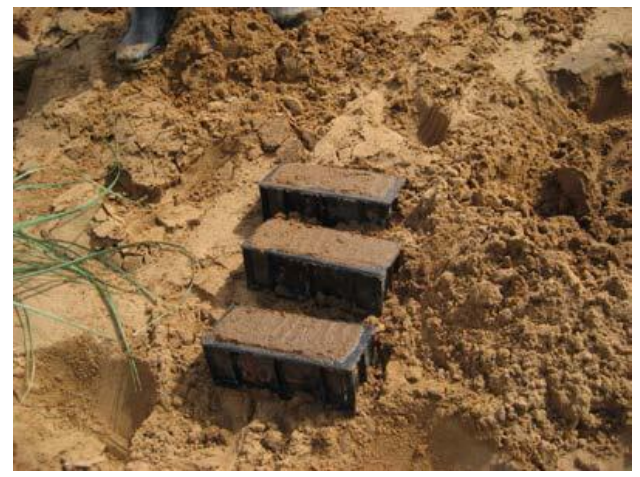

and (b)

Fig. 8 Specimen of reinforced modified sodium silicate grout

A reinforced modified sodium silicate grout specimen was made for indoor testing (Fig. 8(a) and (b)). The physical and mechanical indices of the reinforced modified sodium silicate grout are listed in Table 3.

Table 3

Physical and mechanical indexes of reinforced modified sodium silicate grout

\begin{tabular}{lllllll}
$\begin{array}{l}\text { Water } \\
\text { content } \\
(\%)\end{array}$ & $\begin{array}{lllll}\text { Unit weight } \\
\left(\mathrm{N} / \mathrm{m}^{3} \times 10^{4}\right)\end{array}$ & $\begin{array}{l}\text { Coefficient of } \\
\text { compressibility } \\
\left(\mathrm{MPa}^{-1} \times 10^{-3}\right)\end{array}$ & $\begin{array}{l}\text { Modulus of } \\
\text { compression } \\
(\mathrm{MPa})\end{array}$ & $\begin{array}{l}\text { Internal } \\
\text { friction } \\
\text { angle } \\
\left({ }^{\circ}\right)\end{array}$ & $\begin{array}{l}\text { Cohesive } \\
(\mathrm{MPa})\end{array}$ & $\begin{array}{l}\text { Void } \\
\text { ratio }\end{array}$ \\
\hline 17.33 & 1.24 & 1.3 & 13.15 & 25.31 & 0.05 & 0.751 \\
\hline
\end{tabular}

284 The sand specimen was cured in air for two days. Its uniaxial compressive strength was $2850.2 \mathrm{MPa}$, and its permeability coefficient was $6.83 \times 10^{-6}$; thus, it was essentially an 286 impermeable body. In addition, the durability values of the sand specimen were 287 different after curing in water, air, and buried sand. The sand specimen was buried in 288 the water and sand layers, and its strength did not decrease after three months. After 289 curing in air for one day, white crystals appeared on the surface of the specimen; 290 moreover, the surface was loose, and peeled off after one week.

\section{$291 \quad 3.2$ Analysis of grouting effect}

3.2.1 Study on the injectability of cement grout under different water-cement ratios

294 Increasing the fluidity of a grout is an effective measure for improving its permeability. 295 One commonly used method for cement grout is to increase the water-cement ratio. 296 This is generally based on using large water-cement ratio cement suspension, especially 
297 for grouting in smaller cracks, so as to improve the fluidity and dispersion of the grout. 298 As shown in Table 4, when the water-cement ratio of the superfine cement grout was $2991: 1$, the grouting volume was $16 \mathrm{~L}$, and when the water-cement ratio was $1.5: 1$, the 300 grouting volume was 28.5 L. For ordinary Portland cement grout, the small increase 301 was ascribed to the poor injectability of the grout, i.e., the ordinary cement had large 302 particles, and could not penetrate into the gaps of the aeolian sand formations. 
305 Grout volumes of grouts with various water-cement ratios

Water-cement ratio Grout Volumes, L

Ordinary cement grout

$0.8: 1$

$1: 1$

$1.5: 1$

Superfine cement grout

$1: 1$

\section{6}

\section{5}

The deposition for the cement grout with the high water-cement ratio occurred throughout the movement in the fissures. As the deposition thickness increased, the pressure transmission and flow velocity changed until a certain section was blocked and closed. Both the grouting pressure and consistency affected the compactness of the

310 filling body. When the water-cement ratio reached a certain level, the fluidity of the 311 cement grout was no longer significantly improved, as the deposition process had 312 become a controlling factor affecting its movement in the fissures. Increasing the water313 cement ratio to a very high level did not make much sense for improving the fluidity of 314 the grout. As shown in Table 4, when the water-cement ratio of the superfine cement 315 grout increased from 1.5:1 to 2:1, the grouting volume only increased by $4.5 \%$.

\section{$316 \quad 3.2 .2$ Analysis of the injectability of different materials in aeolian sand layer}

317 Table 5 shows the grouting volumes of the three different grouting materials for a single 318 pipe. The water-cement ratios of the ordinary cement grout and superfine cement grout 319 were 1:1 and 1.5:1, respectively. With regard to injectability in aeolian sand formations, 320 the chemical grout was stronger than the suspension-type grout, and the grouting 321 volume was three to four times that of ordinary cement grout.

322 It can be seen from Table 5 that the permeability of the modified sodium silicate was 323 the best at up to $10 \mathrm{~cm}$, followed by superfine cement at approximately $4 \mathrm{~cm}$, and 
ordinary cement grout had the smallest penetration radius of approximately $2 \mathrm{~cm}$, i.e., it was almost non-permeable. This was related to the type and particles of the grout.

Table 5

Grout volumes of grouts with various water-cement ratios

\begin{tabular}{|c|c|c|}
\hline Grouting material & Grout Volumes, L & Diffusion radius, $\mathrm{cm}$ \\
\hline Ordinary cement grout & 14.5 & 3 \\
\hline Superfine grout & 28.5 & 5 \\
\hline Modified sodium silicate grout & 50.1 & 10 \\
\hline
\end{tabular}

In general, the permeability of a suspended grout composed of solid particulate materials, for example, cement, clay, and fly ash, primarily depends on the particle size and fluidity of the grout. When the sizes of the cracks or pores are smaller than the diameter of the grout particles, effective grouting cannot be implemented. It is generally believed that only when the cracks or pores are more than three times larger than the coarsest particles in terms of size can it be used for grouting. If they are smaller than this limit, the coarsest particles may be blocked in the cracks; thus, they will rapidly form a filter layer, so that other smaller particles cannot penetrate. At present, the ordinary cement produced in China has a particle diameter of approximately $50 \mu \mathrm{m}$ as the main component, and the thickest particles reach $80 \mu \mathrm{m}$. The particle diameter of the aeolian sand of the Shenmu No. 1 Tunnel is primarily distributed between 75 and $500 \mu \mathrm{m}$, and the distance between particles is $10-20 \mu \mathrm{m}$. As such, particles of ordinary cement grout cannot be injected; the grout consolidates around the steel pipe, and cannot penetrate and diffuse.

342 The average particle size of the superfine cement grout was $4 \mu \mathrm{m}$. Therefore, according 343 to theoretical calculations, it could be injected. However, owing to the small particles 344 of the grout, segregation and sedimentation during the penetration process tended to 345 occur, and grout accumulated at the entrance of the fissure to form a grout layer. 346 Therefore, the penetration depth was limited, and the reinforcing effect was not 347 satisfactory.

348 Compared with suspended grout, the modified sodium silicate grout had low viscosity 349 and the best pourability, but the gel time had a great influence on the permeability. The 350 control of the gel time should be strengthened to obtain an ideal penetration range.

\section{Construction technology of aeolian sand tunnel}

352 An aeolian sand stratum has low cohesion and poor self-stability, collapses easily 353 during excavation, and construction therein is difficult. Until now, there have been 
relatively few tunnel projects in the aeolian sand areas of China. In addition, many issues need to be addressed urgently, such as a lack of construction experience, imperfect construction technologies and methods, and a lack of well-formed, systematic, and applicable construction modes. To discuss the construction technologies for aeolian sand tunnels, we first investigated the construction approaches to related aeolian sand tunnels. The projects that have been completed recently are listed in Table 6 .

360 Table 6

361 Projects in aeolian sand formations in China

\begin{tabular}{|c|c|c|c|}
\hline Tunnel & Type of advance support & $\begin{array}{l}\text { Construction } \\
\text { method }\end{array}$ & Notes \\
\hline $\begin{array}{l}\text { New Xingshumao } \\
\text { Tunnel }\end{array}$ & $\begin{array}{l}\text { Horizontal jet grouting } \\
\text { pile, advanced large pipe } \\
\text { shed grouting, advanced } \\
\text { small pipe grouting }\end{array}$ & $\begin{array}{l}\text { Cross diaphragm } \\
\text { (CRD), bench } \\
\text { construction }\end{array}$ & $\begin{array}{l}\text { Shenmu- } \\
\text { shuozhou } \\
\text { Railway }\end{array}$ \\
\hline $\begin{array}{l}\text { Shahalamao } \\
\text { Tunnel }\end{array}$ & $\begin{array}{l}\text { Horizontal jet grouting } \\
\text { pile }\end{array}$ & $\begin{array}{l}\text { Reserved core } \\
\text { soil and bench } \\
\text { construction }\end{array}$ & $\begin{array}{l}\text { Baotou-Xi'an } \\
\text { Railway }\end{array}$ \\
\hline Liuwu Tunnel & $\begin{array}{l}\text { Advanced large pipe } \\
\text { shed grouting }\end{array}$ & $\begin{array}{l}\text { bench } \\
\text { construction }\end{array}$ & $\begin{array}{l}\text { Qinghai-Tibet } \\
\text { Railway }\end{array}$ \\
\hline $\begin{array}{l}\text { New Xiangshawan } \\
\text { Tunnel }\end{array}$ & $\begin{array}{l}\text { Advanced large pipe } \\
\text { shed grouting, advanced } \\
\text { small pipe grouting }\end{array}$ & $\begin{array}{l}\text { Reserved core } \\
\text { soil and short } \\
\text { bench } \\
\text { construction }\end{array}$ & $\begin{array}{l}\text { Double track } \\
\text { electrified } \\
\text { railway tunnels }\end{array}$ \\
\hline Huoshatu Tunnel & $\begin{array}{l}\text { Double-layer advanced } \\
\text { small pipe grouting }\end{array}$ & $\begin{array}{l}\text { Short bench } \\
\text { construction }\end{array}$ & $\begin{array}{l}\text { New Baotou- } \\
\text { shenmu } \\
\text { Railway }\end{array}$ \\
\hline
\end{tabular}

\subsection{Numerical model}

363 As per the majority of the existing numerical studies (e.g. Qiu et al., 2012; Zheng et

364 al., 2012;), a finite difference method can effectively solve the problems of

365 construction technology. In this study, $\mathrm{FLAC}^{3 \mathrm{D}}$ was adopted for the analysis. In the

366 establishment and analysis of the numerical model, we made the following

367 assumptions. First, the initial stress field of the formation did not consider tectonic

368 stress; only its geostatic stress was considered. The effects of the advanced support

369 and bolt reinforcement were achieved by increasing the surrounding rock parameters.

370 To fully reflect and compare the effect of the advanced support, the initial support

371 was activated after the excavation calculation was completed.

372 To ensure sufficient solution accuracy, the general model boundary was three to five 
times the tunnel diameter, and the semi-infinite boundary was simplified to a finite boundary, so as to eliminate the influence of boundary effects. Simultaneously, the normal displacement of each boundary surface was constrained around the model, the bottom surface was completely constrained, and the top surface of the model was a free surface. Based on this, the width direction (x direction) of this model was $100 \mathrm{~m}$, and the height direction (z direction) was $36.4 \mathrm{~m}$ below the bottom of the invert and $27 \mathrm{~m}$ above the vault; that is, the vertical direction was, in total, $73.8 \mathrm{~m}$. The length direction (y-direction) was $1 \mathrm{~m}$.

In this numerical simulation, the physical and mechanical parameters of the aeolian sand were determined through experiments; the parameters of the bottom sandstone and each reinforcement ring were determined by a combination of field experiments and literature data. The parameters of the shotcrete and molded concrete were determined in accordance with the "Specifications for Design of Highway Tunnels" (JTG D70/22014). The detailed parameters are listed in Table 7.

\section{Table 7}

Parameters for numerical simulation

\begin{tabular}{|c|c|c|c|c|c|c|}
\hline Element & $\begin{array}{l}\text { Unit } \\
\text { weight } \\
\left(\mathrm{kN} / \mathrm{m}^{3}\right)\end{array}$ & $\begin{array}{l}\text { Poisson } \\
\text { ratio } \mu\end{array}$ & $\begin{array}{l}\text { Elastic } \\
\text { modulus } \\
(\mathrm{GPa})\end{array}$ & $\begin{array}{l}\text { Cohesion } \\
\text { (MPa) }\end{array}$ & $\begin{array}{l}\text { Internal } \\
\text { friction } \\
\text { angle }\left(^{\circ}\right)\end{array}$ & $\begin{array}{l}\text { Depth of } \\
\text { reinforcing } \\
\text { ring }(\mathrm{m})\end{array}$ \\
\hline Aeolian sand & 17.2 & 0.4 & 0.021 & 0.011 & 27 & I \\
\hline Bottom sand & 19.1 & 0.35 & 1 & 0.1 & 27 & / \\
\hline $\begin{array}{l}\text { Reinforcing } \\
\text { ring by large } \\
\text { pipe shed }\end{array}$ & 18.7 & 0.35 & 0.24 & 0.06 & 30 & 0.5 \\
\hline $\begin{array}{l}\text { Reinforcing } \\
\text { ring by small } \\
\text { pipe }\end{array}$ & 18.2 & 0.35 & 0.13 & 0.05 & 30 & 0.7 \\
\hline $\begin{array}{l}\text { Reinforcing } \\
\text { ring by } \\
\text { horizontal jet } \\
\text { grouting pile }\end{array}$ & 19 & 0.3 & 4 & 0.58 & 35 & 0.6 \\
\hline $\begin{array}{l}\text { Strengthening } \\
\text { area by } \\
\text { anchors }\end{array}$ & 17.5 & 0.38 & 0.04 & 0.02 & 28 & 4.0 \\
\hline Shotcrete & 23 & 0.25 & 23 & l & I & 0.3 \\
\hline Secondary & 25 & 0.2 & 31 & 1 & 1 & 0.6 \\
\hline
\end{tabular}


lining

389 The thickness of the reinforcement ring referred to the radial size of the effective 390 reinforcement shell formed by the advance support and anchor in the formation, 391 comprehensively considering the design parameters of the large pipe shed, small pipe, 392 horizontal jet grouting pile, and anchor (including the pipe diameter, pipe length, and 393 separation distance) and grouting diffusion radius. By combining the physical and 394 mechanical properties of aeolian sand formation and the purpose of numerical 395 simulation, the soil and the secondary lining adopted the Mohr-Coulomb model and the 396 elastic model, respectively, and solid elements were used for simulation. The initial 397 support adopted the shell element of the structural elements for the simulation.

398 The numerical model is shown in Figs. 9-14. Among them, the difference in the 399 advanced support model is only shown in the size of the reinforcement ring; therefore, 400 only one of them is listed as an example.

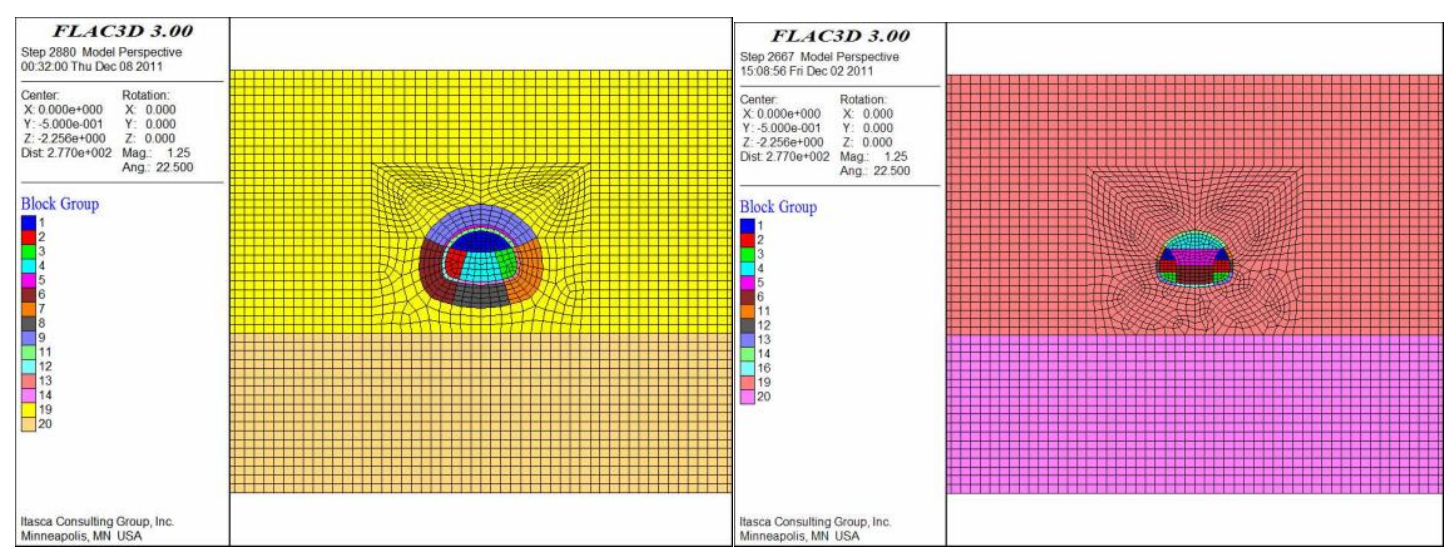

402 Fig. 9 Numerical model of advanced support Fig. 10 Double-sided pit 403 method

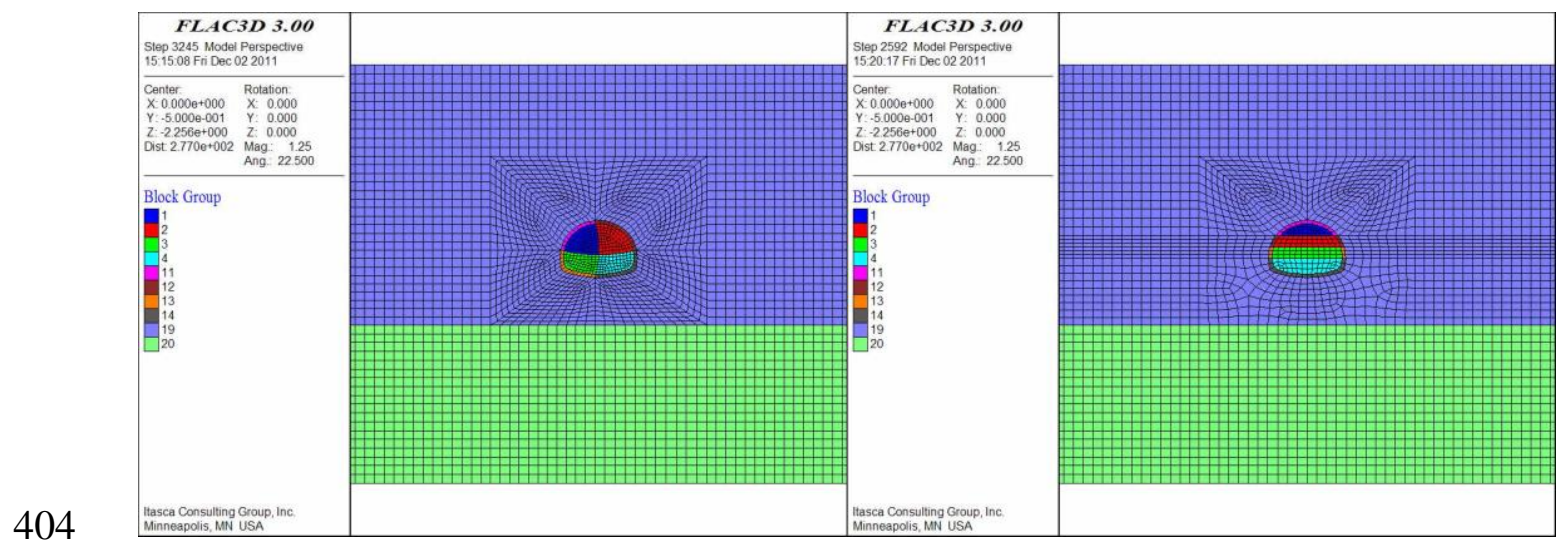

405 Fig. 11 Cross diaphragm (CRD) method

Fig. 12 Bench cut method 


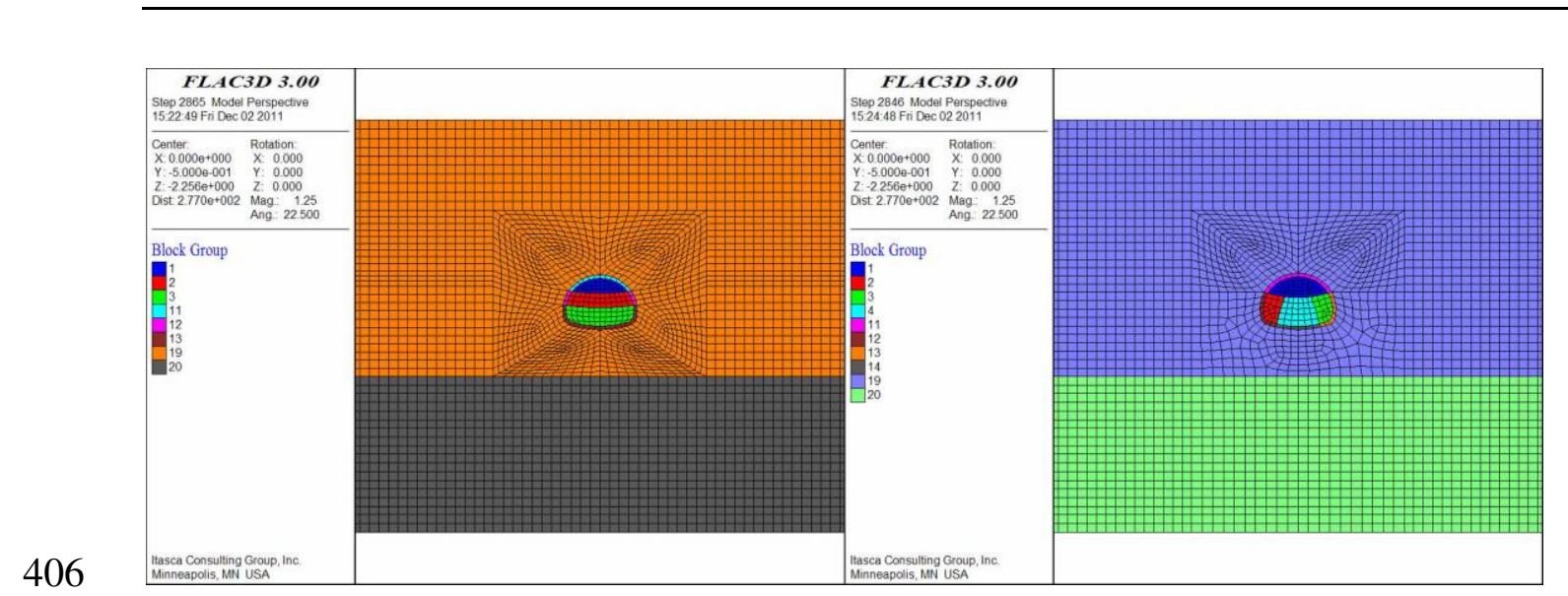

407 Fig. 13 Three-bench method with temporary invert Fig. 14 Benching partial 408 excavation method with temporary invert

$409 \quad 4.2$ Analysis of numerical simulation results

$410 \quad$ 4.2.1 Comparison of advanced support methods

411 Table 8

412 Total settlement of surrounding rock at different support methods (unit: $\mathrm{mm}$ )

\begin{tabular}{lllll}
\hline Support methods & $\begin{array}{l}\text { Surface } \\
\text { subsidence }\end{array}$ & $\begin{array}{l}\text { Vault } \\
\text { settlement }\end{array}$ & $\begin{array}{l}\text { Heave at the } \\
\text { bottom plate }\end{array}$ & $\begin{array}{l}\text { Horizontal } \\
\text { settlement }\end{array}$ \\
\hline $\begin{array}{l}\text { Non advance } \\
\text { support }\end{array}$ \\
$\begin{array}{l}\text { Advanced small } \\
\text { pipe grouting }\end{array}$ \\
$\begin{array}{l}\text { Advanced large } \\
\text { pipe shed grouting }\end{array}$ \\
$\begin{array}{l}\text { Horizontal jet } \\
\text { grouting pile }\end{array}$
\end{tabular}

413 Table 9

414 Percentage decline of vault settlement at different support methods

Support methods Percentage decline of vault settlement at different support methods

Non advance support

Advanced small pipe grouting $\quad 8 \%$ compared with non-advance support

Advanced large pipe shed 12\% compared with non-advance support, 3\% grouting compared with advanced small pipe grouting 
$25 \%$ compared with non-advance support, $18 \%$ Horizontal jet grouting pile compared with advanced small pipe grouting, $15 \%$ compared with advanced large pipe shed grouting

415 Table 10

416 Internal force of primary support at different support methods

\begin{tabular}{|c|c|c|}
\hline Support methods & $\begin{array}{l}\text { Maximum bend } \\
\text { moment }(\mathrm{kN} \cdot \mathrm{m})\end{array}$ & Maximum axial force $(\mathrm{kN})$ \\
\hline Non advance support & & \\
\hline Advanced small pipe grouting & & \\
\hline $\begin{array}{l}\text { Advanced large pipe shed } \\
\text { grouting }\end{array}$ & & \\
\hline Horizontal jet grouting pile & & \\
\hline
\end{tabular}


420 Stress of secondary lining at different support methods (unit: MPa)

\begin{tabular}{|c|c|c|c|}
\hline Support methods & $\begin{array}{l}\text { Maximum } \\
\text { stress }\end{array}$ & $\begin{array}{l}\text { Maximum } \\
\text { stress }\end{array}$ & compression \\
\hline Non advance support & & & \\
\hline $\begin{array}{l}\text { Advanced small pipe } \\
\text { grouting }\end{array}$ & & & \\
\hline $\begin{array}{l}\text { Advanced large pipe shed } \\
\text { grouting }\end{array}$ & & & \\
\hline $\begin{array}{l}\text { Horizontal jet grouting } \\
\text { pile }\end{array}$ & & & \\
\hline
\end{tabular}

From Tables $8-11$, it can be seen that with the increase in the stiffness of the advanced support, the axial force of the initial support increases, the bending moment decreases, the compressive stress of the second lining increases, and the tensile stress decreases. In short, it can be seen that the horizontal jet grouting pile method has the best control effect on surrounding rock deformation and settlement, followed by the large pipe shed grouting method; the small pipe grouting method has the worst effect.

In actual projects, the horizontal jet grouting pile has a complicated construction technology and a long construction period, but its sand-fixing effect, deformation, and settlement control effects are better than those of advanced small and large pipe sheds, and can effectively solve the technical problems in the construction of aeolian sand tunnels, while ensuring the stability of the surrounding rock and construction safety. Compared with horizontal jet grouting piles, the construction technology of advanced large pipe sheds is relatively simple and the construction period is relatively short, meeting the practical requirements for many projects. The key to its successful application in aeolian sand tunnels is the grouting effect. The annular distance and length of the small pipe should be determined reasonably, depending on the diffusion range and sliding surface of the sand body.

\subsubsection{Comparison of construction methods}

(1) Double-sided pit method

It can be seen from the numerical simulation results of the construction process of the double-sided pit method that there are many divisions during the construction process that cause large disturbances. The full-section closure time of the primary support is long, but each section is closed immediately after excavation; therefore, the deformation caused by construction is small, the ability to control the surrounding rock deformation is strong, and the construction safety is high. Notably, the structure is 
subject to complex forces, and part of the structure bears a relatively large force. The following points should be noted during the construction.

The vault settlement caused by the excavation of the upper part of the middle head pit accounts for approximately $65 \%$ of the final settlement. Attention should be paid during construction, and temporary support should be added when necessary to control the settlement of the vault in a timely manner.

During construction, the primary support bears large forces locally; thus, the deformation monitoring and observation of the primary support should be strengthened. Meanwhile, reinforcement must be performed when necessary to prevent local damage.

(2) Cross diaphragm (CRD) method

456 From analyzing the numerical results from the cross diaphragm (CRD) method, it can 457 be seen that the CRD method adopts partial construction, and adds temporary support. 458 Its ability to control the surrounding rock deformation is relatively strong, the 459 deformation is small, and the construction safety is high, but the structural force is also 460 relatively high and complex. Compared with the double-sided pit method, the CRD 461 method has a larger construction area, and the deformation caused by the construction 462 is also relatively large. In addition, the vertical temporary support is subject to greater 463 stress during construction; consequently, monitoring and protection should be 464 strengthened.

\section{5 (3) Bench-cut method}

466 By analyzing the numerical results from the bench cut method, it can be seen that the 467 bench cut method has poor control ability regarding the surrounding rock deformation, 468 leading to wide distribution area of the plastic zone. The following points should be 469 noted during such construction.

$470 \square$ The vault settlement caused by the construction of the upper bench accounts for the 471 largest proportion of the final settlement (approximately 75\%).

$472 \square$ During construction, stress concentrations are likely to occur at the bottom corners 473 of every bench; these can be reinforced by grouting, or by adding lock-foot anchors and 474 spraying concrete at the bottom of the primary support to increase the strength of the 475 surrounding rock or reduce the load.

$476 \square$ The trend of the vault and surrounding rock moving to the tunnel clearance is evident, 477 and the deformation is large; therefore, monitoring and measurement should be 478 strengthened to prevent invasion.

479 (4) Three-bench method with a temporary invert

480 By analyzing the numerical results of the three-bench method with a temporary invert, 481 it can be seen that this method increases the temporary invert, and its surrounding rock 482 deformation control ability is improved relative to that the bench cut method. However, 
the deformation is still large, and the plastic zone is wider. The main reason is that the settlement of the vault caused by construction primarily occurs during the construction of the upper step, but the temporary invert is placed at the bottom of the middle step, making it difficult to effectively play a role. The recommended construction precautions are the same as those for the bench cut method.

\section{(5) Benching partial excavation method with a temporary invert}

From the analysis of the numerical simulation results of the construction process of the benching partial excavation method with a temporary invert, it can be seen that the surrounding rock deformation control ability is greatly improved relative to that of the bench cut method and three-bench method with a temporary invert. The main reason is that it places the temporary invert at the bottom of the upper step; thus, the deformation of the surrounding rock and the settlement of the vault can be controlled in time. Simultaneously, the core soil of the lower step provides effective support to the closed support system of the upper step.

The settlement of the vault caused by the upper step construction accounts for approximately $89 \%$ of the final settlement. Therefore, settlement control of the upper step should be considered during such construction. In addition, the soil in the middle of the lower step has a good supporting effect on the supporting system, and protection should be strengthened during construction; shotcrete can be used for sealing if necessary.

\section{(6) Comparison of construction methods}

From the perspective of the surrounding rock deformation, the double-sided pit method has more section divisions and the best control effect on the surrounding rock deformation. The CRD method has relatively large section divisions, and the settlement control effect is the second-best. The bench cut method has the worst ability to control deformation. The three-bench method with a temporary invert improves the control effect compared with the bench cut method owing to the addition of the temporary invert, but the disturbance of upper step excavation is an important part of its deformation causes, and accounts for the largest proportion of the final deformation; moreover, placing the temporary invert at the bottom of the middle step makes it miss the best opportunity for deformation control. The benching partial excavation method with a temporary invert shows improvement over the three-bench method with a temporary invert, that is, the temporary invert is placed at the bottom of the upper step to control the deformation of the surrounding rock in time; consequently, its deformation control ability is greatly enhanced. (Table 12)

\section{Table 12}

Final displacement pf surrounding rock at various construction methods (unit: mm)

Construction Surface Vault settlementBottom heave Horizontal




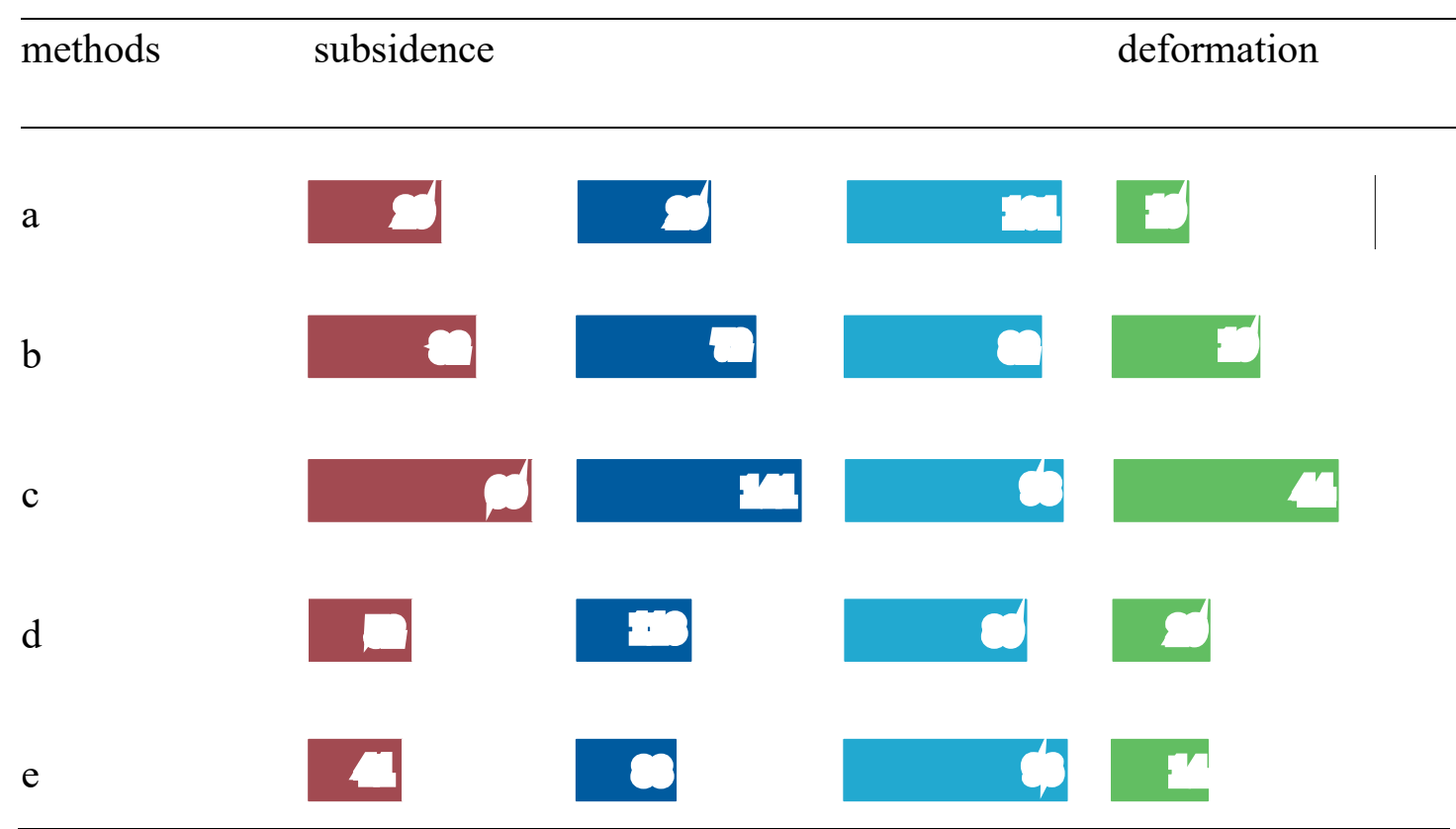

Note: Here, a denotes the double-sided pit method, b denotes the CRD method, c denotes the bench cut method, $d$ denotes the three-bench method with a temporary invert, and e denotes the benching partial excavation method with a temporary invert.

In terms of the initial support force, the double-sided pit method and CRD method effectively control the surrounding rock deformation by reducing the excavation area and increasing the temporary support. Simultaneously, the internal force of the initial support increases, and the structural force becomes complicated. In the bench cut method, the internal force of the structure is relatively small after the surrounding rock pressure is released to a certain extent.

In summary, the double-sided pit method and CRD method have the best settlement control effects, the highest construction safety, complex structural forces, and large internal forces; the settlement control effect of the benching partial excavation method with a temporary invert is the second-best, and the construction safety is general; the three-bench method with a temporary invert has a poor settlement control effect and poor construction safety; and the bench cut method has the worst settlement control effect and worst construction safety.

\subsection{Analysis of construction schemes}

\subsubsection{Different construction schemes}

538 (1) Advanced small pipe grouting (circular spacing $20 \mathrm{~cm}$ ) + four-step method

539 At the beginning of construction, a comprehensive analysis was conducted according 540 to the tunnel geological conditions, construction period, project investment, and so on. 541 It was believed that the small pipe grouting combined with the four-step core soil 542 method has a low construction cost and fast excavation speed. Therefore, this scheme 543 was preferred for construction purposes. However, through practical application, it was 
found that this scheme is not suitable for aeolian sand formations. During construction, the sand leakage and sand sliding at the tunnel face and side walls were serious, resulting in a funnel (approximately $2 \mathrm{~m}$ in diameter and $1.5 \mathrm{~m}$ in depth). There were several transverse cracks on the surface in front of the face. The crack spacing was approximately $0.5-1.0 \mathrm{~m}$ and the widths were $2-4 \mathrm{~cm}$. After excavation of the tunnel, the initial support settlement was excessively large, and the limit was severely invaded. The maximum intrusion limit was $90 \mathrm{~cm}$, and the steel arch changed. The construction progress was very slow, and only $20 \mathrm{~m}$ was constructed for more than three months.

(2) Advanced large pipe shed grouting + three-bench method with a temporary invert

In response to the problems in the construction, the advanced small pipe grouting was changed to advanced large pipe shed grouting. In terms of construction methods, i.e., the comprehensive comparison of the double-sided pit method, CRD method, and bench method with a temporary invert, it was believed that although the double-sided pit method and CRD method could effectively control deformation, the construction cost is high, and the process is relatively complicated and slow. Therefore, based on the original bench cut method, a temporary invert was added, and the four steps were changed to a three-step excavation, that is, the three-bench method with a temporary invert. This method not only had the characteristics of a simple procedure and fast progress of the bench method, but also added a temporary invert and enhanced the ability to control deformation.

(3) Horizontal jet grouting piles + benching partial excavation method with a temporary invert

Through timely adjustment, the large pipe shed was changed to horizontal jet grouting piles. Through practical application, the sand-fixing effects of the horizontal jet grouting piles were evident, and the phenomenon of sand leakage was effectively contained. At the same time, the three steps were adjusted to two steps: improving the initial support force of the upper step, reducing the initial support joints, increasing the vertical braces, and controlling the settlement and deformation of the vault in time. The actual application proved the expected results.

\subsubsection{Comparison of controlling deformation at different construction schemes}

Three representative tunnel sections were selected for analysis of the deformation control ability (Table 13). The measured data regarding the peripheral displacement convergence and vault settlement are shown in Fig. 15 and Fig. 16.

Table 13

General information of tunnel sections

\begin{tabular}{lllll} 
Mileage & K91 +180 & K91 215 & ZK91+220 & \\
\hline Construction & Small & pipe & Large pipe shed + Horizontal & jet \\
\hline
\end{tabular}




\begin{tabular}{|c|c|c|c|}
\hline schemes & $\begin{array}{l}\text { grouting }+ \text { four- } \\
\text { step method }\end{array}$ & $\begin{array}{l}\text { three-bench } \\
\text { method with } \\
\text { temporary invert }\end{array}$ & $\begin{array}{l}\text { grouting pile } \\
\text { benching partial } \\
\text { excavation method } \\
\text { with temporary } \\
\text { invert }\end{array}$ \\
\hline Cover depth & $29 \mathrm{~m}$ & $29 \mathrm{~m}$ & $29 \mathrm{~m}$ \\
\hline
\end{tabular}

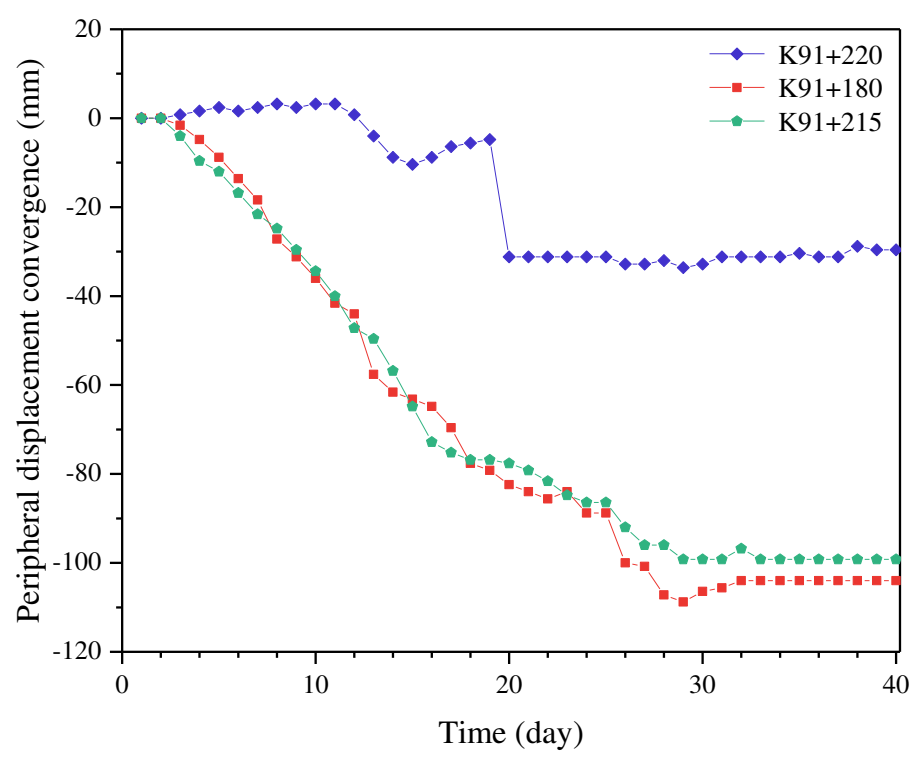

579

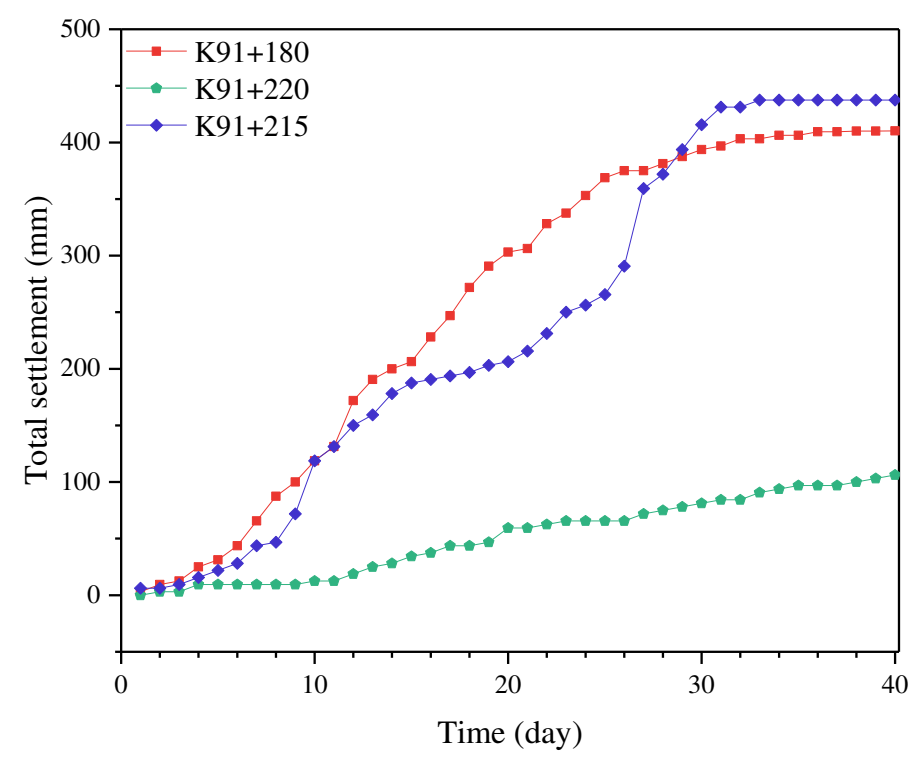


Through the numerical comparison of the convergence and the vault settlement, it can be found that the vault settlements caused by the "small pipe grouting + four-step method" and the "large pipe shed grouting + three-bench method with a temporary invert" are 3.9 times and 4.2 times that caused by the "horizontal jet grouting pile + benching partial excavation method with a temporary invert", respectively, and the data for convergence are 3 times and 3.6 times, respectively.

Therefore, it can be considered that in the construction of aeolian sand tunnels, the "horizontal jet grouting pile + benching partial excavation method with a temporary invert" has the best effect in regards the control of settlement and deformation, and has evident advantages relative to the other two schemes.

\subsection{Suggestions for tunnel construction in aeolian sand strata}

594 Through the above research, the following suggestions are provided.

595 (1) Advanced support

596 Horizontal jet grouting piles should be adopted for advance support; when conditions are restricted, such as by capital or the construction period, under the premise of ensuring the grouting effect, advanced large pipe shed grouting can be selected. The advanced small pipe grouting method should be used as a supplement to solve the problems of sand leakage caused by the increase in the spaces between pipe sheds with the progress of the pipe shed system; when advanced small pipe grouting is used as the

602 primary advanced support method, it should be arranged densely, or in the double-layer 603 form.

604 (2) Construction method

605 In the case of strict control requirements for surface subsidence, the double-sided pit 606 method or CRD method should be adopted, and when there is no strict control 607 requirement for the surface subsidence, it is recommended to adopt the benching partial 608 excavation method with a temporary invert. These feature few excavation steps and 609 flexible construction systems that can control the settlement and deformation of the 610 vault in time; the three-bench temporary invert method and the bench method without 611 a temporary invert should not be used.

\section{Conclusions}

613 (1) Ordinary cement grout has a large particle size, and is difficult to inject into aeolian 614 sand layers with a pore size of $10 \mu \mathrm{m}$; moreover, the cement particles are suspended in 615 the slurry. Even if the particle sizes are smaller than the pores of the sand layer, the 616 filtration of the sand layer causes an extremely small permeability range, and the grout 617 may consolidate on the surroundings of the grouting holes.

618 (2) The superfine cement grout has a small particle size, with an average particle size 619 of $4 \mu \mathrm{m}$. Theoretically, it can be injected into an aeolian sand layer with a pore size of 
$62010 \mu \mathrm{m}$, but actual field tests show that the grouting effect is not significantly different

621 from that of ordinary cement; this is because sedimentation is prone to occur, resulting 622 in poor stability.

623 (3) The modified sodium silicate grout has good permeability, but the gel time is short, 624 blockage in the pipe often occurs in the test, and the proportioning process is more 625 complicated. After grouting, the strength of the reinforced body is low $(0.2 \mathrm{MPa})$, and 626 it can easily weather and break after exposure.

627 (4) Horizontal jet grouting piles should be adopted for advance support; to ensure the 628 grouting effect, advanced large pipe shed grouting should be selected, and the advanced 629 small pipe grouting method should be used as a supplement.

630 (5) In the case of strict control requirements for surface subsidence, the double-sided 631 pit method or CRD method should be adopted, and when there is no strict control 632 requirement for surface subsidence, it is recommended to adopt the benching partial 633 excavation method with a temporary invert. There are few excavation steps and flexible 634 construction systems that can control the settlement and deformation of the vault in 635 time. The three-bench temporary invert method and bench method without a temporary 636 invert should not be used.

\section{Acknowledgement}

638 This study was supported by the National Natural Science Foundation for the General 639 Project of China (Grant No. 51478044, 51678062 and 51878060).

\section{$640 \quad$ References}

641 Dong Changsong, Huang Junwen, Xiao Jun. Study on construction programs of highway tunnels in aeolian sand areas. Tunnel Construction. 2011, 31(02):202-207.

643 Fan Kangjia. Study on the mechanical properties of support structure for shallow buried aeolian sand tunnel based on vertical jet grouting pile. 2017, Xi'an, Chang'an University.

Gao Jingyao. Study of instability characteristics of Tunnel Face in Aeolian sand. 2019, Chengdu, Southwest Jiaotong University.

Jin Bangyuan. The construction technology of plateau tunnel through aeolian and sand deposits. Tibet Science and Technology. 2006, 7:28-31. (in Chinese)

Li Yugen, Zhang Huimei, Liu Guangxiu, Hu Dawei, Ma Xiangrong. Multi-scale study on mechanical property and strength prediction of aeolian sand concrete. Construction and Building Materials. 2020,247(6):118538.

Liu Yujie. Study of construction mechanical behavior and key technology of tunnel in the aeolian sand. 2009, Chengdu, Southwest Jiaotong University. 
657 Liu Zichu. Engineering Properties and the Application of the Wind-blown sand. 2012, Tianjin, Tianjin University.

Qi Yanbing, Chen Tao, Manoj K. Shukla, Chang Qingrui. Using soil minerals to investigate desert expansion in northern Shaanxi Province, China. Aeolian Research. 2020, 43(4):100577.

Qiu Yuliang, Yao Hongzhi, Hu Xiaoyong, Zheng Wankun, Shi Yutong. Mechanical behavior in the construction of large span highway tunnel in aeolian sand strata. China Journal of Highway and Transport, 2012,25(03):112-119. (in Chinese)

Specifications for Design of Highway Tunnels (JTG D70/2-2014). China Communications Press Co., Ltd, Beijing, China, 2014.

Wang Shimin, He Chuan, Nie Liang, Zhang Guangchao. Study on the long-term performance of cementsodium silicate grout and its impact on segment lining structure in synchronous backfill grouting of shield tunnels. 2019, Tunnelling and Underground Space Technology. 2019, 92(10):103015.

Wang Xueji, Wang Zhen, Liu Gang. Comparison between the horizontal jet grouting pile and vertical jet grouting pile applied in the aeolian sand tunnel. Highway, 2017,62(04):330-336. (in Chinese)

Wang Xunming, Hua Ting, Zhu Bingqi, Lang Lili, Zhang Caixia. Geochemical characteristics of the finegrained component of surficial deposits from dust source areas in northwestern China. Aeolian Research. 2018, 34(10):18-26.

Yang Zuowei, Gao Xin, Lei Jiaqiang. Fuzzy comprehensive risk evaluation of aeolian disasters in

Ye Fei, Qin Nan, Liang Xing, Ouyang Aohui, Qin Zhou, Su Enjie. Analyses of the defects in highway

Yan Qixiang, Duan Jingchuan, Liu Gang, Geng Ping. Application and research of risk assessment on Xinjiang, Northwest China. Aeolian Research. 2021, 48(01), 100647 tunnels in China. Tunnelling and Underground Space Technology. 2021, 107(1):103658.

Yuan Yao, Shen Shuilong, Wang Zhifeng, Wu Huaina. Automatic pressure-control equipment for horizontal jet-grouting. Automation in Construction. 2016, 69(9):11-20.

Zhang Deyuan. 2009. Study on the Engineering Characteristics of aeolian sand in Mu Us Desert. Chang'an University. caused by sand deposition: Simulation and experimentation. Aeolian Research. 2020, 34(4), 100578 . control in aeolian sand tunnel construction. Highway, 2012(01):222-226. (in Chinese) 
Zhang Wengang, Li Yongqin, Goh A.T.C., Zhang Runhong. Numerical study of the performance of jet 691 grout piles for braced excavations in soft clay. Computers and Geotechnics. 2020, 124(8):103631.

\section{Author statement}

693 Xing Liang: Conceptualization, Methodology, Formal analysis, Investigation, Writing 694 - Original Draft; Fei Ye: Conceptualization, Methodology, Formal analysis, 695 Investigation, Writing -Supervision, Funding acquisition; Xiaoming Liang: 696 Conceptualization, Methodology, Formal analysis, Investigation, Writing;

\section{Declaration of interests}

698 The authors declare that they have no known competing financial interests or personal 699 relationships that could have appeared to influence the work reported in this paper. 